\title{
Recombinant factor VIIa for variceal bleeding in liver cirrhosis: still only a hope
}

\author{
Xingshun $\mathrm{Qi}^{1}$, Chun $\mathrm{Ye}^{2}$, Xiaozhong Guo ${ }^{1}$
}

\author{
${ }^{1}$ Liver Cirrhosis Study Group, Department of Gastroenterology, General Hospital \\ of Shenyang Military Area, Shenyang, China \\ ${ }^{2}$ Department of General Surgery, General Hospital of Shenyang Military Area, \\ Shenyang, China
}

Submitted: 10 February 2015

Accepted: 6 April 2015

Arch Med Sci 2017; 13, 2: 496-499

DOl: https://doi.org/10.5114/aoms.2017.65331

Copyright $\odot 2017$ Termedia \& Banach

At present, recombinant activated coagulation factor VII ( $\mathrm{rFVIIa}$ ) is approved for the treatment of hemophilia A and B [1, 2]. The use of rFVIla may also be considered as an adjunctive treatment option for blunt trauma, post-partum hemorrhage, uncontrolled bleeding in surgical patients, and bleeding after cardiac surgery [3]. However, the use of rFVIIla for the treatment of upper gastrointestinal bleeding remains controversial, especially in cirrhotic patients. Several small-scale studies suggest that rFVIIa can effectively correct the coagulation status in patients with liver diseases without any severe adverse events, thereby decreasing the risk of bleeding related to percutaneous approaches, such as liver biopsy (Table I) [4-8]. On the other hand, rFVIIa can achieve hemostasis in patients with liver cirrhosis [9]. A small case series reported by Romero-Castro et al. analyzed the hemostatic efficacy of $4.8 \mathrm{mg}$ rFVIla in 8 cirrhotic patients with severe active bleeding from esophageal varices [7]. The rates of hemostasis, rebleeding, and mortality were $100 \%(8 / 8), 25 \%(2 / 8)$, and $50 \%$ $(4 / 8)$, respectively. However, two multicenter, double-blinded, randomized controlled trials (RCTs) by Bosch et al. achieved negative results regarding the efficacy and safety of rFVIla for the treatment of upper gastrointestinal bleeding (UGIB) in cirrhotic patients [10, 11].

In the first RCT, 245 cirrhotic patients with active UGIB requiring hospitalization and volume replacement therapy were randomized into the rFVIIa and placebo groups between April 2001 and April 2002 [10]. The source of UGIB was variceal in $66 \%$ of patients, non-variceal in $29 \%$, and unknown in 5\%. Among them, 118 patients treated with rFVIIa and 119 patients treated with placebo were finally analyzed for the primary outcome. A composite primary endpoint was composed of the failure to control acute bleeding within $24 \mathrm{~h}$ after the first dose of trial product, failure to prevent rebleeding between $24 \mathrm{~h}$ and 5 days, and death over a 5 -day trial period. The overall analysis found that the primary endpoint was not significantly different between rFVIla and placebo groups (14\% $(16 / 1180)$ vs. $16 \%(19 / 119), p=0.72)$. The subgroup analysis of a highrisk population (i.e., variceal bleeders with Child-Pugh class B-C) demonstrated that the rate of primary endpoint was significantly higher in the rFVlla group than in the placebo group (8\% (5/62) vs. $23 \%(15 / 64), p=$ 0.03 ). Accordingly, it was concluded that rFVIla might be effective for cirrhotic patients with variceal bleeding and Child-Pugh class B-C, but not for those with non-variceal UGIB and/or mild liver dysfunction.

\author{
Corresponding authors: \\ Dr. Xingshun Qi \\ Prof. Xiaozhong Guo \\ Department \\ of Gastroenterology \\ General Hospital of \\ Shenyang Military Area \\ Shenyang, 110840 China \\ Phone: +86 2428897603 \\ Fax: +862428851113 \\ E-mail: xingshunqi@126.com, \\ guo_xiao_zhong@126.com
}




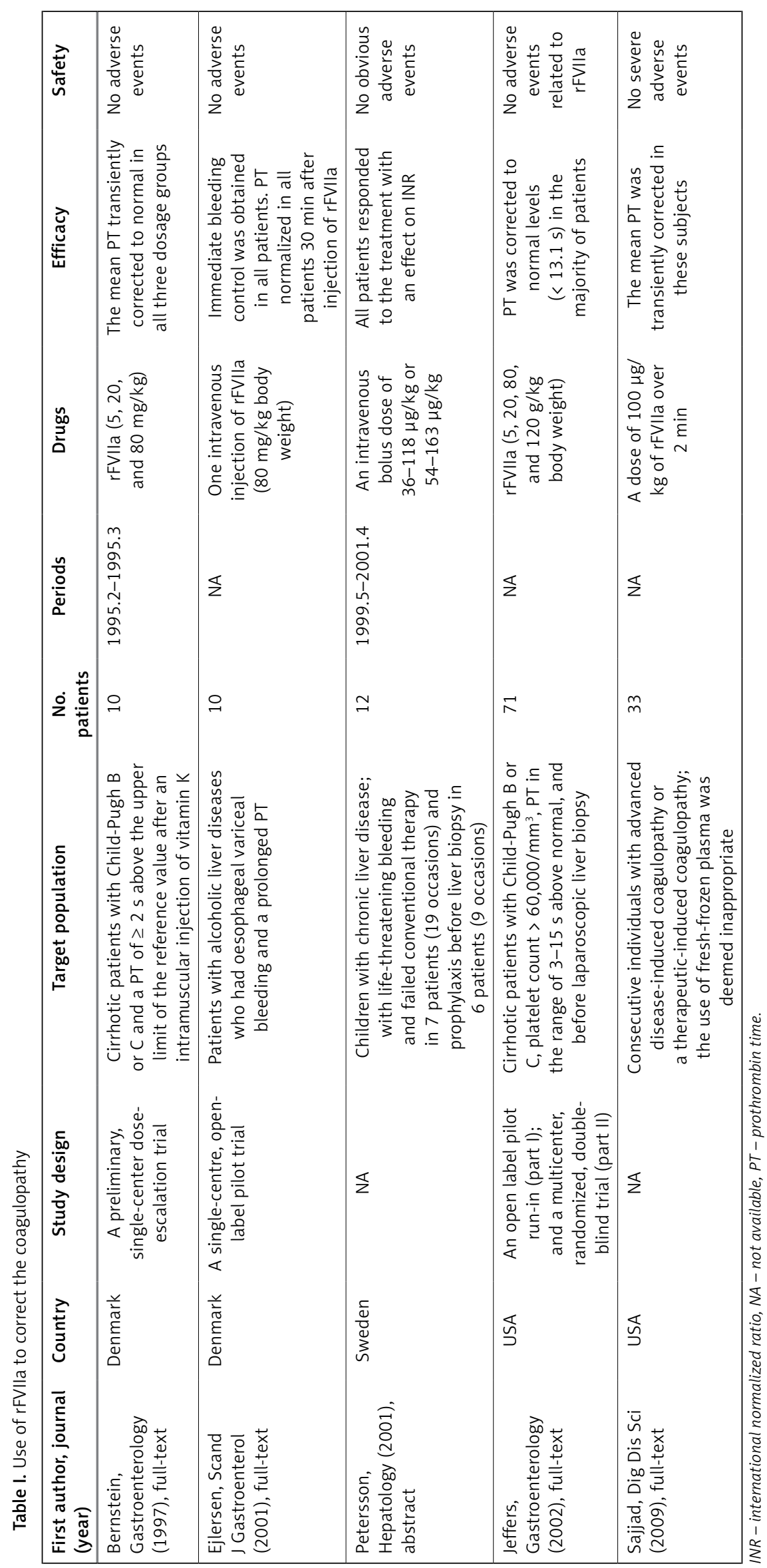


Based on the findings from the first RCT [10], the investigators selected the cirrhotic patients with Child-Pugh class B and C and variceal bleeding for the second RCT [11]. Between April 2004 and August 2006, a total of 256 subjects were randomized into the placebo $(n=86), 600 \mu \mathrm{g} / \mathrm{kg}$ rFVIIa $(n=85)$, and $300 \mu \mathrm{g} / \mathrm{kg}$ rFVIIa $(n=85)$ groups [11]. All of them had a Child-Pugh score of $>8$ points (Child-Pugh B/C: 26\%/74\%). The primary endpoint was the treatment failure according to the Baveno II-IV criteria, including the failure to control acute bleeding within $24 \mathrm{~h}$, failure to prevent clinically significant rebleeding, or death within 5 days. The rate of primary endpoint was similar between placebo and $600 \mu \mathrm{g} /$ kg rFVIla groups (23\% (20/86) vs. 20\% (17/85); odds ratio $=0.8, p=0.37)$. Notably, the patients treated with $300 \mu \mathrm{g} / \mathrm{kg} \mathrm{rFVIla}$ had a lower rate of composite endpoint (13\% (11/85)). However, the investigators did not compare the efficacy between $300 \mu \mathrm{g} / \mathrm{kg}$ rFVIIa and placebo groups according to the statistical analysis plan. Herein, we used the raw data to re-calculate the statistical significance by using a $\chi^{2}$ test, but the difference was not significant (23\% (20/86) vs. $13 \%$ (11/85), $p=0.080)$. Accordingly, the previous conclusion achieved by the subgroup analysis of the first RCT was not supported, because rFVIla had no significant effect on the primary composite endpoint in high-risk patients.

Marti-Carvajal et al. conducted a Cochrane systematic review and meta-analysis of the two RCTs to analyze the outcome of rFVIla for UGIB in patients with liver diseases $[12,13]$. Compared with placebo, rFVIlla did not reduce the risk of 5- and 42day mortality or increase the risk of adverse events (neither serious adverse events nor thromboembolic events were not significantly different between the two groups). Thus, the systematic reviewers did not find any evidence to accept or reject the use of rFVIIla for UGIB in patients with liver diseases.

Despite this, the investigators did not give up the idea of rFVIla for bleeding in liver cirrhosis. More recently, Bendtsen et al. conducted a meta-analysis of the individual patient data from the two previous RCTs [14]. Notably, the 5-day failure rate was significantly lower in cirrhotic patients with active bleeding at endoscopy and a ChildPugh score $>8$ receiving $\mathrm{rFVIla}$ than in those receiving placebo (odds ratio $=0.53,95 \%$ confidence interval: 0.29-0.97, $p=0.04$ ) [14]. Notably, the upper limit of the $95 \%$ confidence intervals was close to 1 . In addition, only a fixed-effects model was employed according to the result of the $\chi^{2}$ test for the heterogeneity $(p=0.12)$. But the value of $R^{2}=59 \%$ might be neglected. As is well known, the choice of a fixed-effects or random-effects model often depends on the statistical significance of heterogeneity among studies. When $p<0.1$ or $l^{2}>50 \%$ is obtained, a random-effects model is considered appropriate. Indeed, when a random-effects model is employed to update the meta-analysis, the statistical significance disappears (odds ratio $=0.35,95 \%$ confidence interval: $0.06-2.00, p=0.24$ ) (Figure 1).

In addition, the overall meta-analysis by Bendtsen et al. failed to support any significant treatment effect in the intention-to-treat population, but the subgroup meta-analysis achieved a statistical significance in patients with active variceal bleeding at endoscopy, especially in those with a Child-Pugh score > 8 [14]. However, the tests for interaction were not performed among different subgroups. Given that chance could create the imbalance among subgroups, the credibility of the subgroup analysis might be overestimated [15]. The validity of subgroup effects should be assessed to avoid potentially misleading or biased conclusions [16, 17]. Similarly, the subgroup analysis of the first RCT found a significant benefit of rFVIla in the high-risk population [10], but the overall analysis of the second RCT did not support the finding [11]. Therefore, the results of the subgroup analyses should be cautiously interpreted due to their methodological limitations.

In conclusion, apart from its marginal efficacy in the treatment of variceal bleeding, we should never neglect that rFVIIa is too expensive and may increase thromboembolism without any significant survival benefits [18-20]. Accordingly, the use of rFVIla may not be recommended in cirrhotic patients with acute variceal bleeding until positive findings from high-quality studies are reported in a selected population.

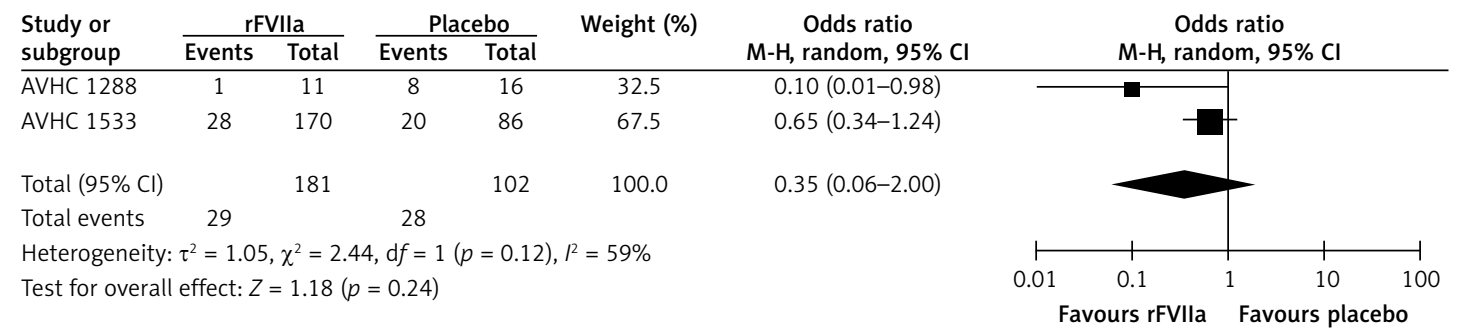

Figure 1. Forest plot of meta-analysis regarding the benefit of rFVIIa for the 5 -day failure rate in cirrhotic patients with active variceal bleeding and a Child-Pugh score $>8$ using a random-effects model 


\section{Acknowledgments}

The first two authors contributed equally to this work.

\section{Conflict of interest}

The authors declare no conflict of interest.

\section{References}

1. Dutta TK, Verma SP. Rational use of recombinant factor VIla in clinical practice. Indian J Hematol Blood Transfus 2014; 30: 85-90.

2. Eshghi P, Mahdavi-Mazdeh $M$, Karimi M, Aghighi $M$. Haemophilia in the developing countries: the Iranian experience. Arch Med Sci 2010; 6: 83-9.

3. Vincent JL, Rossaint R, Riou B, Ozier Y, Zideman D, Spahn DR. Recommendations on the use of recombinant activated factor VII as an adjunctive treatment for massive bleeding: a European perspective. Crit Care 2006; 10: R120.

4. Sajjad S, Garcia M, Malik A, George MM, Van Thiel DH. Use of recombinant factor Vlla to correct the coagulation status of individuals with advanced liver disease prior to a percutaneous liver biopsy. Dig Dis Sci 2009; 54: 1115-9.

5. Bernstein DE, Jeffers L, Erhardtsen E, et al. Recombinant factor VIla corrects prothrombin time in cirrhotic patients: a preliminary study. Gastroenterology 1997; 113: 1930-7.

6. Jeffers L, Chalasani N, Balart L, Pyrsopoulos N, Erhardtsen E. Safety and efficacy of recombinant factor VIla in patients with liver disease undergoing laparoscopic liver biopsy. Gastroenterology 2002; 123: 118-26.

7. Romero-Castro R, Jimenez-Saenz M, Pellicer-Bautista F, et al. Recombinant-activated factor VII as hemostatic therapy in eight cases of severe hemorrhage from esophageal varices. Clin Gastroenterol Hepatol 2004; 2: 78-84.

8. Pettersson M, Fisehler B, Petrini P, Schulman S, Hedner U, Nemeth A. Recombinant activated factor VII in children with liver disease and coagulopathy. A preliminary study. Hepatology 2001; 34: 531A.

9. Mannucci PM, Franchini M. Recombinant factor VIla as haemostatic therapy in advanced liver disease. Blood Transfus 2013; 11: 487-90.

10. Bosch J, Thabut D, Bendtsen F, et al. Recombinant factor VIla for upper gastrointestinal bleeding in patients with cirrhosis: a randomized, double-blind trial. Gastroenterology 2004; 127: 1123-30.

11. Bosch J, Thabut D, Albillos A, et al. Recombinant factor VIla for variceal bleeding in patients with advanced cirrhosis: a randomized, controlled trial. Hepatology 2008; 47: 1604-14.

12. Marti-Carvajal AJ, Karakitsiou DE, Salanti G. Human recombinant activated factor VII for upper gastrointestinal bleeding in patients with liver diseases. Cochrane Database Syst Rev 2012; 3: CD004887.

13. Marti-Carvajal AJ, Salanti G, Marti-Carvajal PI. Human recombinant activated factor VII for upper gastrointestinal bleeding in patients with liver diseases. Cochrane Database Syst Rev 2007; 1: CD004887.

14. Bendtsen F, D'Amico G, Rusch E, et al. Effect of recombinant factor VIla on outcome of acute variceal bleeding: an individual patient based meta-analysis of two controlled trials. J Hepatol 2014; 61: 252-9.
15. Wang R, Lagakos SW, Ware JH, Hunter DJ, Drazen JM. Statistics in medicine: reporting of subgroup analyses in clinical trials. N Engl J Med 2007; 357: 2189-94.

16. Sun X, Briel M, Walter SD, Guyatt GH. Is a subgroup effect believable? Updating criteria to evaluate the credibility of subgroup analyses. BMJ 2010; 340: c117.

17. Sun X, loannidis JP, Agoritsas T, Alba AC, Guyatt G. How to use a subgroup analysis: users' guide to the medical literature. JAMA 2014; 311: 405-11.

18. Sozio MS, Chalasani N. Activated recombinant factor VIla should not be used in patients with refractory variceal bleeding: it is mostly ineffective, is expensive, and may rarely cause serious adverse events. Hepatology 2014; 60: 1786-8.

19. Yank V, Tuohy CV, Logan AC, et al. Systematic review: benefits and harms of in-hospital use of recombinant factor VIla for off-label indications. Ann Intern Med 2011; 154: 529-40.

20. Levi M, Levy JH, Andersen HF, Truloff D. Safety of recombinant activated factor VII in randomized clinical trials. N Engl J Med 2010; 363: 1791-800. 